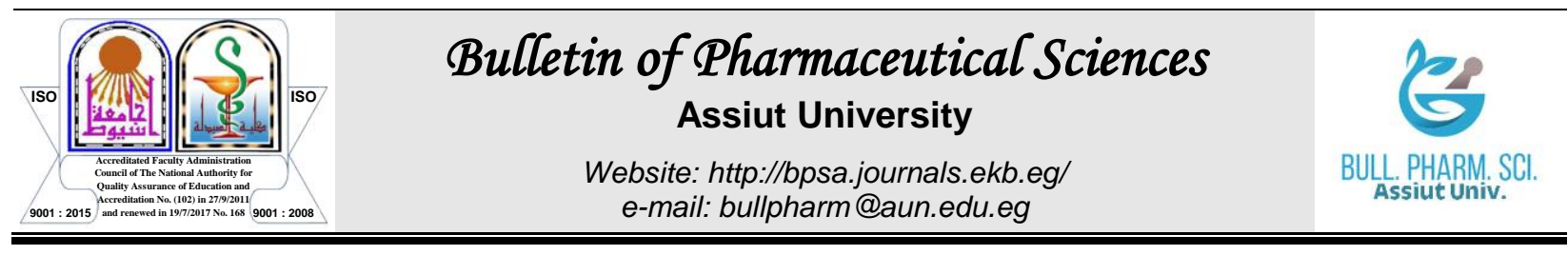

\title{
CURCUMIN'S IMPACT ON CARBAMAZEPINE PHARMACOKINETICS AT VARIOUS DOSES IN RABBITS
}

\author{
Issam Mohammed Abushammala \\ Department of Pharmaceutics and Industrial Pharmacy, Faculty of Pharmacy, Al-Azhar \\ University- Gaza, P.O Box: 1277, Palestine
}

The purpose of this study is to explore the influence of preadministration of Curcumin (CUR), at two distinct dosages (60 and $90 \mathrm{mg} / \mathrm{kg}$ body weight per day, 8 days, p.o), on the pharmacokinetic $(P K)$ profile of Carbamazepine $(C B Z)$ in rabbits. Eighteen rabbits were divided randomly into 3 groups (6 rabbits per group). Control group were given (20 $\mathrm{mg} / \mathrm{kg}$ of CBZ, as single dose, p.o.). The first and second test groups were given CUR (60 and $90 \mathrm{mg} / \mathrm{kg}$ body weight per day, 8 days, p.o $)$. On the eighth day, CBZ $(20 \mathrm{mg} / \mathrm{kg})$ was administered one hour after giving CUR's last dose. Blood was drawn from a marginal ear vein at various intervals $(0.5,1,1.5,2,2.5,3.5,4,6,12$, and $24 \mathrm{hr}$.$) . CBZ levels in serum were determined$

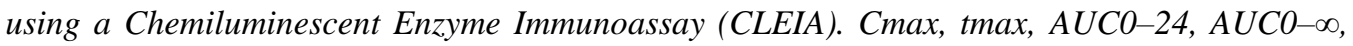
$K e$ and $C L / F$ were calculated. Statistically insignificant differences were found in the different $P K$ parameters of $C B Z$. The results demonstrated that prior treatment of CUR at both concentrations, had no influence on $P K$ parameters of $C B Z$ in rabbits.

\section{INTRODUCTION}

Carbamazepine (CBZ) is used to treat partial seizures, generalized tonic-clonic seizures, trigeminal neuralgia, and bipolar disorders all over the world ${ }^{1}$. Because it has a significant low therapeutic index and a wide inter-individual variation at tolerable doses, therapeutic drug monitoring is necessary ${ }^{2 \& 3}$. Regardless of its clinical approval, CBZ has several PK properties, making it convenient for interaction with co-administered substances, including drugs, herbal products, and food ${ }^{4}$. CYP3A4 is the main enzyme that contributes to CBZ metabolism, leading to the formation of CBZ 10,11-epoxide, which is an active metabolite that participates in the efficacy and toxicity of $\mathrm{CBZ}^{5 \& 6}$. Drug interactions are classified into two categories: pharmacodynamic and PK interactions ${ }^{7-9}$.

In general, the variation in drug PK is related to the absence of a consistent relationship between the used dose of the medicine and its concentration at the action ${ }^{10}$. Medicinal remedies are believed to be natural and secure. However, some of their constituents can modify various metabolizing enzymes and transport systems, which play a significant role in the absorption and disposition of co-administered drugs. Consequently, herb-drug co-administration may initiate herb-drug interactions by altering the function of drug-metabolizing enzymes and/or drug transporters ${ }^{11 \& 12}$.

Curcumin (Diferuloylmethane, CUR), a polyphenol constituent in the spice turmeric, is a specific secondary metabolite of C.Curcuma longa.,C.zedoaria, C.aromatica, C.wenyujin, and C.kwangsiensis ${ }^{13}$. Curcumin is the main chemical compound of Turmeric and proven for its anti-inflammatory, antioxidant, antimutagenic, antidiabetic, antibacterial, hepatoprotective, expectorant and anticancerous pharmacological activities ${ }^{14}$. Several in vitro studies have indicated that CUR inhibits the activity of the CYP3A4 enzyme. Based on these findings, CUR coadministration should increase the oral bioavailability of CYP3A4 substrates ${ }^{15}$. The impact of preadministration of CUR at various doses on the PK profile of CBZ, a CYP 3A4 substrate, is investigated in the present study. 


\section{MATERIALS AND METHODS}

\section{Animals}

Eighteen male rabbits weighted (3.1-3.4 $\mathrm{kg}$ ) divided into three groups (six per group) were selected and used as an animal model for the present PK interaction study. The animals were placed in normal lab circumstances for 12 hours day/night at room temperature, fed improvisationally with nutritional pills and water, while fasting was followed the night before the blood draw.

\section{Design of the study and blood sampling}

Healthy male rabbits $(n=6)$ were used in $\mathrm{PK}$ interaction research experiments involving CUR and CBZ in three groups of animals in a parallel designed manner. In the control group, rabbits were given a volume equivalent to CBZ (20 mg/kg as single dose, p.o.) from an oral suspension of $2 \%$ (Tegretol, Novartis). Serial venous drawing blood samples (1.0-1.5 ml) obtained from rabbits ear marginal vein using special cannula $(21 \mathrm{G})$ at various time intervals: $0.5,1,1.5,2,2.5,3.5,4,6,12$, and 24 hr. postdosing $^{16}$. Meanwhile, rabbits of the first and second test groups were given a volume of CBZ (20 mg/kg as single dose, p.o.) at the same conditions as in the control group along with prepared in aqueous saline suspension a volume equivalent to $(60$ and $90 \mathrm{mg} / \mathrm{kg}$ body weight per day, 8 days, p.o) from CUR capsules (CUR Turmeric $550 \mathrm{mg}$ Jamieson) for eight consecutive days. On the $8^{\text {th }}$ day, CBZ was administered one hour after administering the last dose of CUR suspension, and blood samples were collected from all rabbits of the first and second test groups at the intervals mentioned as in the control group. The serum was collected by centrifuging the blood samples and was stored at $\left(-80^{\circ} \mathrm{C}\right)$ until analysis for CBZ.

\section{Analytical method for CBZ}

The analysis was carried out using an ARCHITECT analyzer 1000 Abbott Laboratories, Abbott Park, IL, USA, utilizing CBZ detection kits that rely on Chemiluminescent Enzyme Immunoassay (CLEIA).

\section{Pharmacokinetic Analysis}

The PK profiles of CBZ in control and herb treated groups were plotted between serum changed the concentration of CBZ versus sampling time. The PK parameters of control and treated test groups were obtained through an independent method (NonCompartmental Approach) WinNonlin Professional Software (Version 6.3, Pharsight Corporation, Cary, NC) and (GraphPad Prism versión 4.00, San Diego, CA, USA). The following $\mathrm{PK}$ parameters were calculated, including $\mathrm{C}_{\max }, \mathrm{t}_{\max }, \mathrm{AUC}_{0-24}, \mathrm{AUC}_{0-\infty}, \mathrm{K}_{\mathrm{e}}$ and $\mathrm{CL} / \mathrm{F}$ for control and test groups. The serum concentrations were used to construct PK profiles by plotting drug concentration-time curves. To determine PK parameters for control and treated with CUR groups of CBZ, all obtained data was subsequently fed into WinNonlin Professional Software (Version 6.3, Pharsight Corporation, Cary, NC) and (GraphPad Prism versión 4.00, San Diego, CA, USA). The non-compartmental PK parameters including maximum serum concentration $\left(\mathrm{C}_{\max }\right)$ and time to reach maximum concentration $\left(\mathrm{t}_{\max }\right)$, area under the concentration curve from 0 to $24 \mathrm{hrs}$. $\left(\mathrm{AUC}_{0-24}\right)$, area under the concentration curve from 0 to infinity $\left(\mathrm{AUC}_{0}\right.$ $\infty)$, terminal elimination rate constant $\left(\mathrm{K}_{\mathrm{e}}\right)$ and total body clearance (CL/F) were calculated.

For each time point in each group, the data is presented as a mean with standard deviation (SD). The differences in CBZ PK parameters between the control and test groups were examined using general linear model techniques and an independent (unpaired) ttest. SPSS (Version 22.0) was used to undertake data analysis that met the significance requirements $(P<0.05)$.

\section{RESULTS AND DISCUSSION}

Serum CBZ concentration-time profiles obtained after p.o. administration of $20 \mathrm{mg} / \mathrm{kg}$ CBZ to rabbits in control and co-administered with CUR (60 and $90 \mathrm{mg} / \mathrm{kg}$ ) in the first and second test groups is shown in Figure 1. The corresponding PK parameters, including $\mathrm{C}_{\max }$, $t_{\max }, \quad \mathrm{AUC}_{0-24}, \quad \mathrm{AUC}_{0-\infty}, \mathrm{K}_{\mathrm{e}}$, and $\mathrm{CL} / \mathrm{F}$ for control and CUR treated test groups are summarized in Table 1. 


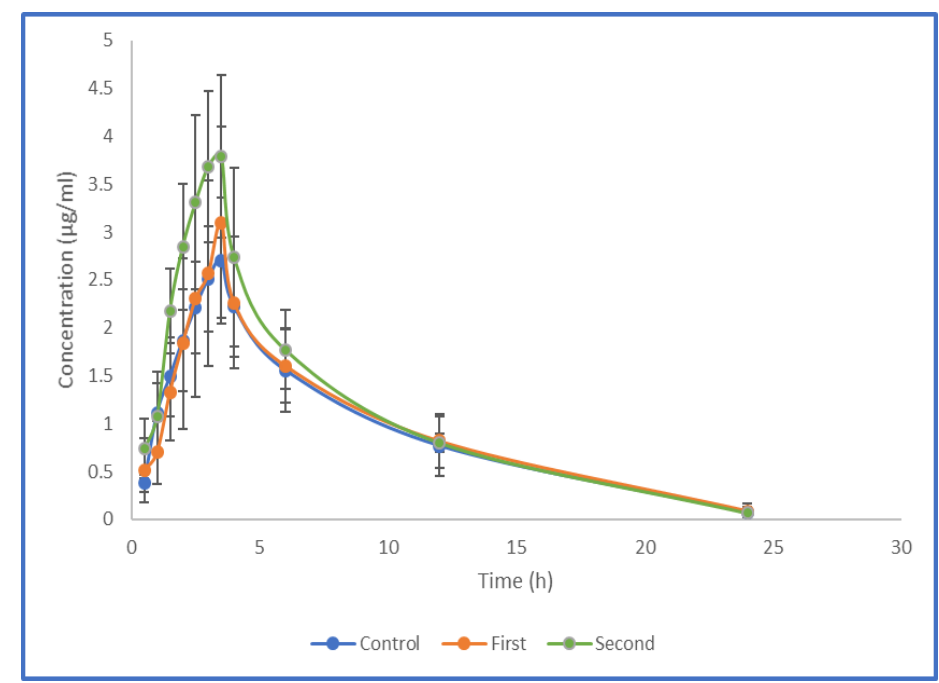

Fig. 1: The plot of the CBZ serum concentration-time profile. Control group: CBZ (20 mg/kg) was p.o administered alone. First and second test groups: CBZ $(20 \mathrm{mg} / \mathrm{kg})$ was co-administered along with CUR (60 and $90 \mathrm{mg} / \mathrm{kg})$, respectively, in rabbits $(\mathrm{n}=6)$.

Table 1: Calculated PK parameters of the control, first and second test groups (6 for each).

\begin{tabular}{|c|c|c|c|}
\hline PK Parameters & Groups & Mean \pm SD & P-value \\
\hline \multirow{3}{*}{${ }^{\mathrm{a}} \mathrm{C}_{\max }(\mu \mathrm{g} / \mathrm{mL})$} & Control group & $2.70 \pm 0.84$ & \multirow[t]{2}{*}{$0.361^{¥}$} \\
\hline & First test group & $3.07 \pm 1.00$ & \\
\hline & Second test group & $3.78 \pm 0.85$ & $0.083^{\S}$ \\
\hline \multirow{3}{*}{$\mathrm{b}^{\mathrm{t}_{\max }}(\mathrm{hr})$} & Control group & $3.10 \pm 0.90$ & \multirow[t]{2}{*}{$0.374^{*}$} \\
\hline & First test group & $3.40 \pm 0.22$ & \\
\hline & Second test group & $3.50 \pm 0.04$ & $0.529^{\S}$ \\
\hline \multirow{3}{*}{${ }^{\mathrm{c}} \mathrm{AUC}_{0-24}(\mu \mathrm{g} * \mathrm{hr} / \mathrm{mL})$} & Control group & $22.80 \pm 6.49$ & \multirow[t]{2}{*}{$0.680^{\ddagger}$} \\
\hline & First test group & $23.25 \pm 7.26$ & \\
\hline & Second test group & $27.10 \pm 5.36$ & $0.562^{8}$ \\
\hline \multirow{3}{*}{${ }^{\mathrm{d}} \mathrm{AUC}_{0-\infty}(\mu \mathrm{g} \mathrm{hr} / \mathrm{mL})$} & Control group & $23.46 \pm 7.10$ & \multirow[t]{2}{*}{$0.686^{\ddagger}$} \\
\hline & First test group & $24.13 \pm 7.94$ & \\
\hline & Second test group & $27.54 \pm 5.39$ & $0.421^{\S}$ \\
\hline \multirow{3}{*}{${ }^{\mathrm{e}} \mathrm{Ke}\left(\mathrm{hr}^{-1}\right)$} & Control group & $0.136 \pm 0.04$ & \multirow[t]{2}{*}{$0.840^{\ddagger}$} \\
\hline & First test group & $0.123 \pm 0.03$ & \\
\hline & Second test group & $0.148 \pm 0.07$ & $0.136^{8}$ \\
\hline \multirow{3}{*}{${ }^{\mathrm{f}} \mathrm{Cl} / \mathrm{F}\left(\mathrm{mL} \mathrm{h}^{-1}\right)$} & Control group & $2.76 \pm 0.91$ & \multirow[t]{2}{*}{$0.838^{\ddagger}$} \\
\hline & First test group & $2.88 \pm 0.98$ & \\
\hline & Second test group & $2.24 \pm 0.43$ & $0.185^{\S}$ \\
\hline
\end{tabular}

$(¥)$ : $P$-value of the differences between the control and first test group; $(\S)$ : $P$-value of the differences between the control and the second test group.

- $\mathrm{P} \leq 0.05$ Statistical significance, SD: Standard deviation, ${ }^{a}$ maximum blood concentration, ${ }^{\mathrm{b}}$ time of peak concentration, "area under the concentration-time profile curve from 0 to 24 hours, area under the concentration-time profile curve from 0 to infinity, ${ }^{\mathrm{e}}$ elimination rate constant and ${ }^{\mathrm{f}}$ total body clearance. 
In the control group, the $\mathrm{C}_{\max }$ of $\mathrm{CBZ}$ was found to be $2.70 \pm 0.84 \mu \mathrm{g} / \mathrm{mL}$, and the $t_{\max }$ was $3.10 \pm 0.90 \mathrm{hr}$. Meanwhile, in the first test group, the $\mathrm{C}_{\max }$ and $\mathrm{t}_{\max }$ were $3.07 \pm 1.0 \mu \mathrm{g} / \mathrm{mL}$ and $3.40 \pm 0.22 \mathrm{hr}$., respectively $(P>0.05)$. The systemic exposures defined by $\mathrm{AUC}_{0-\infty}$ were also similar between the control and first test groups $(23.46 \pm 7.10 \mu \mathrm{g} * \mathrm{hr} / \mathrm{mL}$ vs. $24.13 \pm$ $\left.7.94 \mu \mathrm{g}^{*} \mathrm{hr} / \mathrm{mL} ; P=0.686\right)$. Furthermore, the remaining $\mathrm{PK}$ parameters showed no significant variations, including $\mathrm{AUC}_{0-24}, \mathrm{~K}_{\mathrm{e}}$, and $\mathrm{CL} / \mathrm{F}$ between the two groups (Table 1). Moreover, the comparison of serum concentration-time profiles of $\mathrm{CBZ}$ alone (control group) and treated with CUR $90 \mathrm{mg} / \mathrm{kg}$ (second test group) is shown in Figure 1. Their corresponding PK parameters are given in Table 1 as well. In this case, despite the observed increase in $\mathrm{C}_{\max }$ and $\mathrm{t}_{\max }$ of the second test group compared with the control group, the slight increase in $\mathrm{C}_{\max }$ and $\mathrm{t}_{\max }$ of $\mathrm{CBZ}$ were statistically non-significant $(P>0.05)$. The extent of CBZ absorption (measured by $\mathrm{AUC}_{0-}$ $\left.{ }_{\infty}\right)$ between the control and second test groups was insignificant $(P>0.05)$. Similarly, the PK parameters $\mathrm{k}_{\mathrm{e}}, \mathrm{CL} / \mathrm{F}$, and $\mathrm{AUC}_{0-24}$ between both groups were statistically insignificant $(P>$ 0.05).

Traditional herbal medicine plays an essential role in the treatment of many diseases, such as epilepsy. However, herbal medicine should undergo evidence-based scrutiny due to the deficiency of clear and strong evidence for most herbs' efficacy and toxicity ${ }^{17}$. Besides, the herbs can perform their actions through various mechanisms that may alter the PK profile of the co-administered drug $^{18}$. Therefore, it is highly critical to be aware of the possible interactions of the frequently used herbal medicines $^{19}$. Treatment failure and exacerbation of side effects of drugs with a narrow therapeutic index are related to coadministration of an agent inhibiting or inducing the activity of the cytochrome P450 (P450) enzyme system ${ }^{20 \& 21}$.

CYP3A4 is primarily involved in CBZ metabolism, where the end product of its metabolism is the formation of CBZ 10,11epoxide, an active metabolite that contributes to the toxicity and efficacy of $\mathrm{CBZ}^{5 \& 6}$.

Based on the PK herb-CBZ interactions, the findings summarized in a review article published by Fong and his collaborators showed that a reduction in the plasma level of CBZ results in a decrease in CBZ bioavailability due to the over-activity of the CYP3A4 enzyme when some herbal medicines interact with CBZ. On the contrary, the inhibitory effect on CYP3A4 activity led to an elevation of CBZ plasma level with increased CBZ bioavailability. Furthermore, the PK interaction was statistically insignificant on CBZ bioavailability when other herbs were coadministered with CBZ in vitro/in vivo and human models were shown to be studied ${ }^{4}$.

Previous herb-drug interaction experiments on $\mathrm{CBZ}$, theophylline, and cyclosporine (narrow therapeutic indexed drugs) were published utilizing five to six rabbits that were pretreated with herbal products for 7-8 days ${ }^{22-26}$.

In the present study, statistically insignificant differences in the PK profile of CBZ were observed in the following parameters: $\mathrm{C}_{\max }, \mathrm{t}_{\max }, \mathrm{AUC}_{0-24}, \mathrm{AUC}_{0-\infty}, \mathrm{K}_{\mathrm{e}}$, and $\mathrm{CL} / \mathrm{F}$ compared to the control group when pretreated with CUR at different doses (in the first and second test groups) on the PK profile of $\mathrm{CBZ}$ (P> 0.05). Similar results were obtained by Alkharfy and his research group when they studied the PK interaction between Nigella Sativa and CBZ by using rabbits as an animal model ( $\mathrm{n}=5$ and for eight days). They found that the PK of CBZ does not change with and without Nigella sativa ${ }^{22}$. Also, in another study published by Abushammala et al., demonstrated that the different PK parameters of CBZ were not altered when it was given alone or concurrently with Panax Ginseng by using rabbits as an animal model $(n=6$ and for eight days) ${ }^{23}$.

Regarding CUR, the combination of CUR with prescribed drugs should increase the oral bioavailability of CYP3A4 substrates due to the CYP3A4 inhibition effect ${ }^{15}$. The PK data revealed that CUR-treated animals had significantly altered the PK profile of Norfloxacin in rabbits ${ }^{27}$. Meanwhile, the slight increase in the PK parameters $\mathrm{C}_{\max }$ and $\mathrm{t}_{\max }$ in the CUR treated group when co administered with theophylline was statistically insignificant. Also, the PK profile of Gliclazide was not altered by single-or multiple-doses of CUR pretreated rabbits ${ }^{28}$.

Finally, the study published by Liu and collaborators (when using wistar rats as an animal model for 7 days) found that the 
interaction between Warfarin (a narrow therapeutic index drug) and CUR at a small and medium dose $(25$ and $50 \mathrm{mg} / \mathrm{kg}$ ) had no substantial inhibition effect on the PK parameters of Warfarin. In contrast, the effect was statistically significant at a larger dose of CUR $(100 \mathrm{mg} / \mathrm{kg})^{29}$.

According to our experimental results, the CUR at tested concentrations (60 and 90 $\mathrm{mg} / \mathrm{kg}$ ) for eight days had not altered the PK profile of CBZ or produced a remarkable effect on its profile at a dose of $20 \mathrm{mg} / \mathrm{kg}$. Otherwise, more research projects should be conducted with the aim of giving more explanation of the effect of CUR on the PK of CBZ by using higher CUR doses and/or a longer period of CUR co-administration.

\section{Conclusion}

Pretreatment herb-drug interaction involving CUR and CBZ is the subject of the current study. In the animal model, the interaction between CUR and CBZ was found to be pharmacokinetically insignificant. The PK profile of CBZ was unaffected by coadministration of CBZ with CUR at two different doses. Based on these findings, using CUR in combination with CBZ in an animal model appears to be safe. We need to confirm our findings by using a larger number of animals to reduce inter-individual variability and providing greater CUR doses to check if the CBZ/CUR interaction is significant before they can be used in patients. Simultaneously, delivering CUR and CBZ simultaneously should be done with caution until prospective clinical studies indicate that there is no significant interaction in humans.

\section{Acknowledgment}

The author wanted to express his deepest gratitude and appreciation to all members of Al-Azhar University's Faculty of Pharmacy in Gaza, especially the Department of Pharmaceutics and Industrial Pharmacy, in which the research was conducted.

\section{REFERENCES}

1. G. Ayano, "Bipolar Disorders and Carbamazepine: Pharmacokinetics, Pharmacodynamics, Therapeutic Effects and Indications of Carbamazepine.
Review of Articles", $J$ Neuropsychopharmacol Ment Health, 1(4), 112 (2016).

2. G. C. Anderson, "Pharmacokinetic, pharmacodynamic and targeted pharmacogenetic therapy of antiepileptic drugs", Ther Drug Monit, 30, 173-180 (2008).

3. L. C. Johannessen, S. I. Johannessen, and P. N. Patsalos, "Therapeutic drug monitoring of antiepileptic drugs: current status and future prospects", Expert Opin Drug Metab Toxicol, 16, 227-238 (2020).

4. S. Y. Fong, Q. Gao, and Z. Zuo, "Interaction of carbamazepine with herbs, dietary supplements, and food: A systematic review", Evid Based Complement Alternat Med, 15, 898261 (2013).

5. P. Kang, M. Liao, M. R. Wester, J. S. Leeder, R. E. Pearce, and M. A. Correia, "CYP3A4-Mediated carbamazepine (CBZ) metabolism: formation of a covalent CBZ-CYP3A4 adduct and alteration of the enzyme kinetic profile", Drug Metab Dispos, 36, 490-499 (2008).

6. Y. G. Puranik, A. K. Birnbaum, and S. E. Marino, et al., "Association of carbamazepine major metabolism and transport pathway gene polymorphisms and pharmacokinetics in patients with epilepsy", Pharmacogenomics, 14, 35-45 (2013).

7. P. N. Patsalos, W. Froscher, F. Pisani, and C. M. van Rijn, "The importance of drug interactions in epilepsy therapy", Epilepsia, 43, 365-385 (2002).

8. C. Ioannides, "Pharmacokinetic interactions between herbal remedies and medicinal drugs", Xenobiotica, 32, 451478 (2002).

9. S. F. Zhou, Y. H. Gao, Q. J. Wen, M. Huang, A. L. Xu, and J. W. Paxton, "Interactions of herbs with cytochrome P450", Drug Meta. Rev, 35, 35-98 (2003).

10. P. W. Park, Y. H. Seo, J. Y. Ahn, K. A. Kim, and J. Y. Park, "Effect of CYP3A5*3 genotype on serum carbamazepine concentrations at steady state in Korean epileptic patients", J Clin Pharm Ther, 34, 569-574 (2009). 
11. R. Hermann, and O. Richter von, "Clinical evidence of herbal drugs as perpetrators of pharmacokinetic drug interactions", Planta Med, 78, 1458-1477 (2012).

12. S. B. Kim, L. S. Yoon, and K. S. Kim, et al., "In vitro and in vivo evaluation of the effect of puerarin on hepatic cytochrome P450- mediated drug metabolism", Planta Med, 80, 561-567 (2014).

13. C. Tohda, N. Nakayama, F. Hatanaka, and K. Komatsu," Comparison of Antiinflammatory Activities of Six Curcuma Rhizomes: A Possible Curcuminoidindependent Pathway Mediated by Curcuma phaeocaulis Extract", Evid Based Complement Alternat Med, 3, 255260 (2006).

14. V. Krup, L. H. Prakash, and A. Harini, "Pharmacological Activities of Turmeric (Curcuma longa linn): A Review", $\boldsymbol{J}$ Homeop Ayurv Med, 2, 133 (2013).

15. Y. Hsieh, C. Huang, and S. Yang et al., "Oral intake of curcumin markedly activated CYP 3A4: in vivo and ex-vivo studies", Sci. Rep., 10, 6587 (2015).

16. S. Parasuraman, R. Raveendran, and R. Kesavan, "Blood sample collection in small laboratory animals", J Pharmacol Pharmacother, 1, 87-93 (2010).

17. W. Liu, T. Ge, Z. Pan, Y. Leng, J. Lv, and B. Li, "The effects of herbal medicine on epilepsy", Oncotarget, 8, 48385-48397 (2017).

18. A. Fugh-Berman, "Herb-drug interaction", Lancet, 355, 134-138 (2000).

19. J. Tang, X. Song, M. Zhu, and J. Zhang," Study on the pharmacokinetics drug-drug interaction potential of Glycyrrhiza uralensis, a traditional Chinese medicine, with lidocaine in rats", Phytother Res, 23, 603-607 (2009).

20. F. Pea, and M. Furlanut," Pharmacokinetic aspects of treating infections in the intensive care unit: focus on drug interactions", Clin Pharmacokinet, 40, 833-868 (2001).

21. S. HemaIswarya, and M. Doble," Potential synergism of natural products in the treatment of cancer", Phytother Res, 20, 239-249 (2006).
22. K. M. Alkharfy, F. I. Al-Jenoobi, M. A. Alam, A. M. Al-Mohizea, S. A. AlSuwayeh, H. M. Korashy, R. M. Khan, and I. Muzaffar, "Lepidium sativum but not Nigella sativa affects carbamazepine disposition in an animal model", Drug Metab Lett, 7, 47-51 (2013).

23. I. M. Abushammala, F. K. El-Shaikh Ali, K. F. Abu Shammaleh, M. M. Taha, and M. Y. Miqdad, "Effect of Panax ginseng on Carbamazepine Pharmacokinetics in Rabbits", Turk J Pharm Sci, 25, 17-20 (2021).

24. F. I. Al-Jenoobi, A. Ahad, M. Raish, A. M. Al-Mohizea, and M. A. Alam, "Investigating the Potential Effect of Commiphora myrrha on the Pharmacokinetics of Theophylline, a Narrow Therapeutic Index Drug", Drug Res (Stuttg), 65, 312-316 (2015).

25. A. M. Al-Mohizea, M. Raish, A. Ahad, F. I. Al-Jenoobi, and M. A. Alam, "Pharmacokinetic interaction of Acacia catechu with CYP1A substrate theophylline in rabbits", $\boldsymbol{J}$ Tradit Chin Med, 35, 588-593 (2015).

26. F. I. Al-Jenoobi, S. A. Al-Suwayeh, I. Muzaffar, M. A. Alam, K. M. Al-Kharfy, H. M. Korashy, A. M. Al-Mohizea, and A. M. Raish, "Effects of Nigella sativa and Lepidium sativum on Cyclosporine Pharmacokinetics", BioMed Research Int, 2013, 1-6 (2013).

27. B. H. Pavithra, N. Prakash, and K. Jayakumar, "Modification of pharmacokinetics of norfloxacin following oral administration of curcumin in rabbits", J Vet Sci, 10, 293-297 (2009).

28. L. K Vatsavai, and E. K Kilari, "Influence of curcumin on the pharmacodynamics and pharmacokinetics of gliclazide in animal models", J Exp Pharmacol, 178, 69-76 (2016)

29. A. C. Liu, L. X. Zhao, and H. X. Lou, "Curcumin alters the pharmacokinetics of warfarin and clopidogrel in Wistar rats but has no effect on anticoagulation or antiplatelet aggregation", Planta Med, 79, 971-977 (2013). 


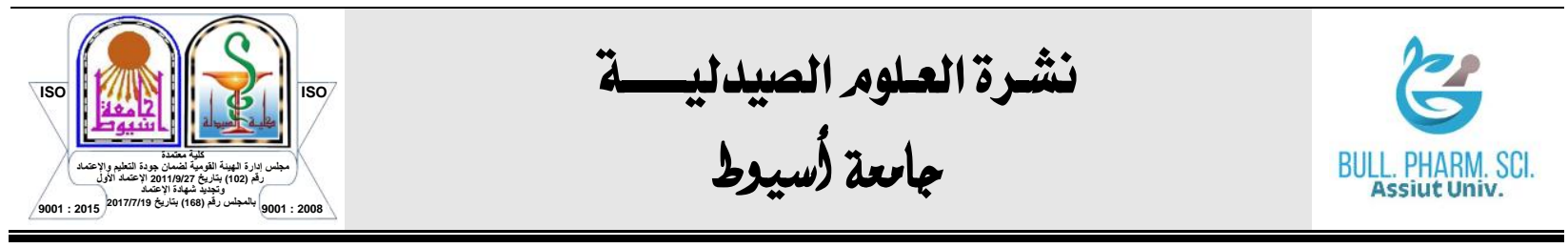

\section{تأثير الكركومين معاملات الحرائك الدوائية للكاربامازيبين في جرعات مختلفة في الأر انب}

\section{عصام محمد أبو شمالة' - مالب}

قسم الصيدلانيات والصيدلة الصناعية ، كلية الصيدلة ، جامعة الأزهر ، غزة ، فلسطين صندوق بريد ITYY

الهدف من هذه الدراسة هو تحديد كيفية تأثير الكركمين (CUR) على الأنى معاملات الحر ائك الدوائية

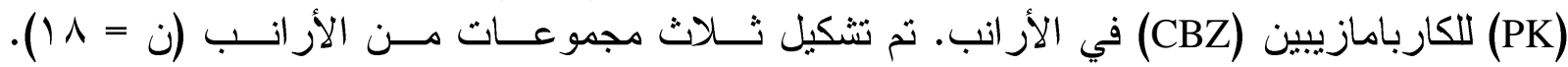

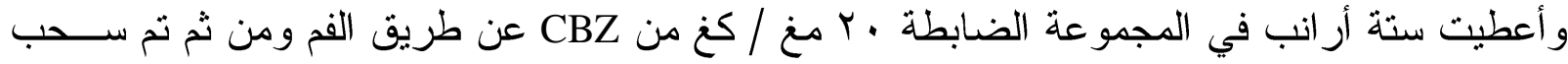

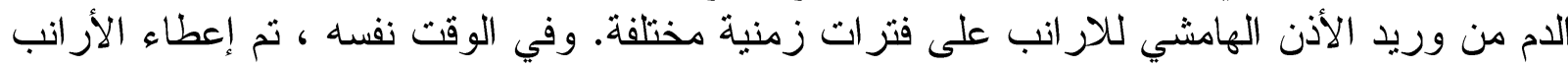

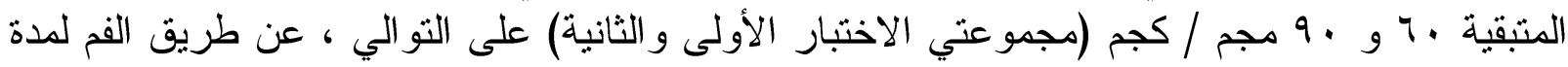

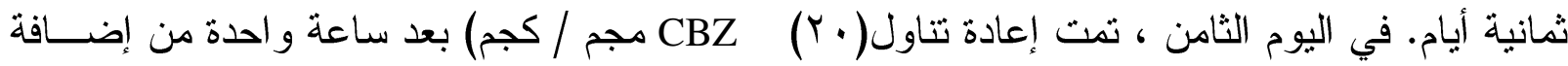

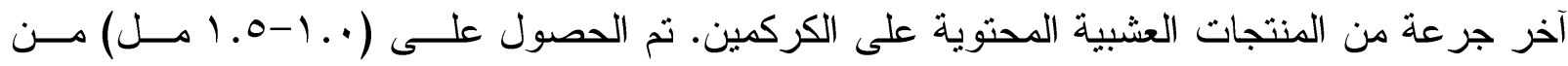

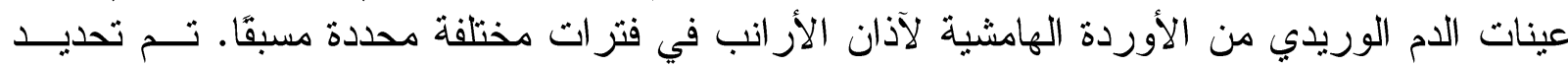

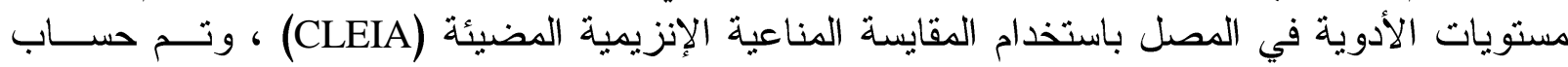

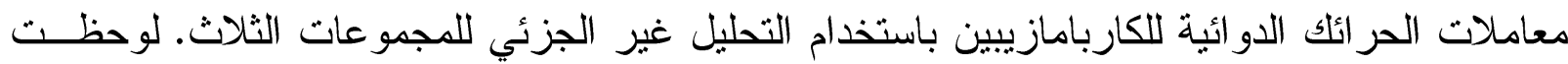

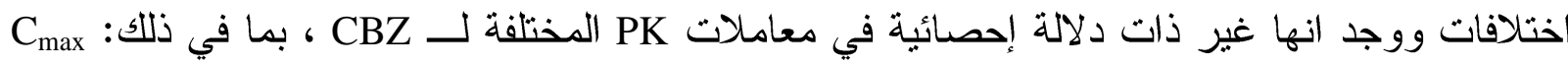

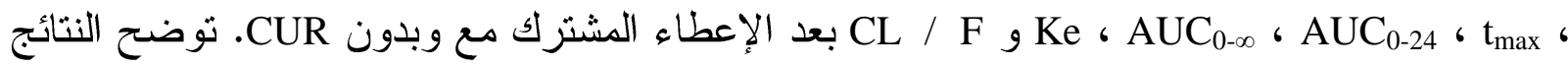

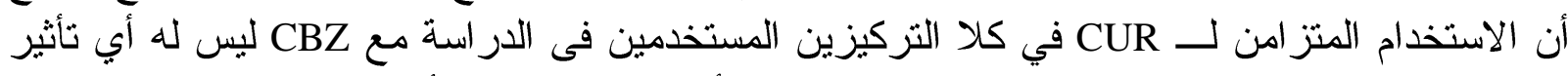

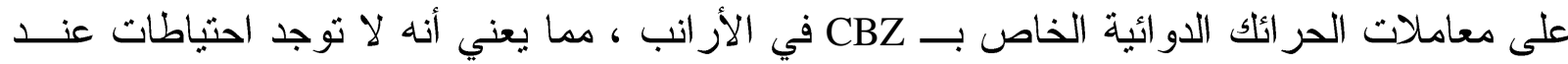
إعطاء CBZ باستخدام CUR. 